\title{
Evaluation of Genetic Divergence for Grain Yield and Its Contributing Traits in Field pea (Pisum sativum L. var. arvense)
}

\author{
Kanhaiya Lal", Rajesh Kumar, Vishal Singh, Amit Kumar Chaudhary, \\ Harikant Yadav and Ashvani Kumar \\ Department of Genetics and Plant Breeding, Narendra Deva University of Agriculture and \\ Technology, Kumarganj, Faizabad-224 229 (U.P.), India \\ *Corresponding author
}

\begin{tabular}{|l|}
\hline K e y w o r d s \\
$\begin{array}{l}\text { Genetic divergence, Field } \\
\text { pea (Pisum sativum } \text { L. } \\
\text { var. arvense), Genetic } \\
\text { variability, Non- } \\
\text { hierarchical Euclidean } \\
\text { cluster analysis, }{ }^{2} \\
\text { values. }\end{array}$ \\
\hline Article Info \\
\hline $\begin{array}{l}\text { Accepted: } \\
\text { 18 May } 2018 \\
\text { Available Online: } \\
\text { 10 June 2018 }\end{array}$ \\
\hline
\end{tabular}

\section{A B S T R A C T}

One hundred twenty genotypes of field pea were evaluated with four check varieties to assess genetic divergence for grain yield and its contributing traits. Significant differences among all the genotypes were recorded for all the characters studied except number of primary branches per plant. All the genotypes were grouped into twelve different nonoverlapping clusters by Non-hierarchical Euclidean cluster analysis on the basis of $\mathrm{D}^{2}$ values. The genotypes of cluster I had highest mean value $(20.585 \mathrm{~g})$ for 100 seed weight. The genotypes of cluster III had highest mean value for seeds per pod (7.074) as well as for pod length (7.984). The genotypes of cluster $\mathrm{V}$ had lowest value for days to $50 \%$ flowering (62.250 days) as well as for days to maturity (114.531 days). The genotypes of cluster VI had highest mean value for harvest index (55.971) followed by biological yield per plant (37.407) and seed yield per plant (20.819). The genotypes of cluster VII had highest value for pods per plant (19.485). The genotypes of cluster XII had highest mean value for plant height (103.127) as well as for branches per plant (2.135). Cluster VI had minimum genotypes namely, FP 14-81, FP 11-72 and EC-507770, these are the best genotypes on the basis of their mean performance for seed yield and its contributing traits. Cluster XI was found largest with twenty genotypes following cluster II \& cluster X (15), cluster VIII (13), cluster IX (12), cluster I (11), cluster III \& VII (9), cluster V (8), cluster XII (5) and cluster IV (4). The highest intra cluster distance was observed within cluster VII (16.392) followed by cluster IX (10.544), cluster X (9.977), cluster I (9.911), cluster VI (8.616), cluster IV (7.866), cluster III (7.707), cluster XI (7.362), cluster XII (6.801), cluster V (6.617) and cluster II (6.616). While lowest intra cluster distance was observed within cluster VIII (5.336). The inter cluster distance between cluster II and cluster VIII was lowest (11.633). The maximum inter cluster distance was recorded between cluster IV and XII (58.308) and between cluster VI and cluster XI (54.180), which suggested that genotypes of these clusters are genetically very diverse to each other and inter mating among these genotypes would be rewarded for improving grain yield. The analysis of character contribution towards genetic divergence indicated that the maximum contributions in manifestation of total genetic divergence were made by plant height, harvest index and days to 50 per cent flowering. 


\section{Introduction}

Fieldpea (Pisum sativum L. var. arvense) is an important pulse crop among rabi pulses and it holds an unique position in the country due to its multiple uses as food, feed and fodder. It is a member of leguminoceae family and it contains, $2 \mathrm{n}=2 \mathrm{x}=14$ chromosomes. Pea has high inherent productivity potential but its production has been on decline and average productivity is miserably low, which may be improved through intercrossing between genetic divergent lines. Therefore, it becomes imperative to identify genetic divergent lines. Taking these problems, in the present study, an attempt has been made to identify genetic divergent lines in the germplasm which is under evaluation to select the potential parents for breeding programme to attain anticipated improvement in grain yield of field pea.

\section{Materials and Methods}

One hundred twenty genotypes of field pea were evaluated with four check varieties in augmented block design during Rabi 20152016at Genetics and Plant Breeding Research Farm of Narendra Deva University of Agriculture and Technology, Narendra Nagar, Kumarganj, Faizabad (U.P.).The seeds of different genotypes were available with Pulses Section of the university. The experiment was laid out in Augmented block design. The entire experimental field was divided into 12 blocks of equal size and each block had 14 plots. Out of 14 plots in a block, 10 plots were used for accommodating the un-replicated test genotypes while 4 were allocated to the four check varieties, viz., Rachna, Ambika, HFP 8909 and HUDP 15. The four checks were randomly allocated along with the test genotypes in a block. Each plot consisted of a single row of $4 \mathrm{~m}$ length, following inter and intra row spacing $30 \mathrm{~cm}$ and $10 \mathrm{~cm}$, respectively. Recommended cultural practices were practiced to raise a good crop. The observations were recorded on randomly selected five competitive plants from each genotypes for nine characters, viz., Plant height $(\mathrm{cm})$, number of primary branches per plant, number of pods per plant, pod length $(\mathrm{cm})$, number of seeds per pod, 100-seed weight, biological yield per plant, harvest index and seed yield per plant (g), while two characters viz., days to 50 per cent flowering, days to maturity were recorded on the plot basis. In order to study genetic divergence these data were subjected to $\mathrm{D}^{2}$ analysis and their estimates are presented in Table 1, 2, 3 and 4. Analysis employed TOCHER's and WARD's methods so as to group the genotypes into different clusters.

\section{Results and Discussion}

The selection of suitable diverse parents for hybridization is an important step for any crop improvement programme to get desired recombinants. The importance of genetic divergence in plant breeding has also been emphasized by several researchers. Therefore, this study was carried out by using Nonhierarchical Euclidean cluster analysis by method which was described by Beale, 1969 and Spark, 1973 to assess the genetic divergence in fieldpea genotypes for seed yield and its contributing traits. Through WARD's method all the genotypes were grouped into twelve different non-overlapping clusters in which cluster VI was found to be smallest having three genotypes namely, FP 14-81, FP 11-72 and EC-507770, these genotypes were found to be best genotypes on the basis of their mean performance for seed yield and its contributing traits. These genotypes were also found to be more divergent with the genotypes of cluster XI. The cluster XI was found to be largest one involving 20 genotypes followed by cluster II, X, VIII, IX, I, III, VII, V, XII and IV having $15,15,13,12,11,9,9,8,5$ and 4 genotypes respectively. The intra-cluster distance (D) 
ranged from 5.336 to 16.392 while, inter cluster distance (D) ranged from 11.633 to 58.308 , indicated high divergence among the different genotypes. The highest intra cluster distance was observed in cluster VII (16.392) followed by cluster IX, X, I, VI, IV, III, XI, XII, V, II. While, the lowest intra cluster value was recorded in case of cluster VIII (5.336). The maximum inter cluster distance was recorded between cluster IV and XII (58.308) and between cluster VI and cluster XI (54.180), which suggested that the members of these clusters are genetically very diverse to each other and intermating among the genotypes of these clusters would be rewarded to get a wide spectrum of variability and liberation of transgressive segregants as well as for improving grain yield. The inter cluster distance between cluster II and cluster VIII (11.633) was lowest. Parihar et al., (2014) also assessed one hundred forty genotypes of fieldpea to the genetic divergence for various agronomic traits and stated that all the accessions were significantly different for the traits and a wide range of variability exists for most of the traits. The D values for 120 genotypes and four check varieties ranged from 5.336 to 58.308 illustrated the substantial amount of genetic diversity among the population.

The clusters mean for eleven characters in fieldpea genotypes are given in Table 3 . Perusal of table showed considerable differences among the clusters mean for different traits. The genotypes of cluster I had highest mean value for 100-seed weight $(20.585 \mathrm{~g})$ and had lowest mean value for pods per plant (12.813) as well as for number of primary branches per plant (1.105). The genotypes of cluster II had highest mean value for days to 50 per cent flowering (125.706 days). The genotypes of cluster III had highest mean value for seeds per pod (7.074) as well as for pod length (7.984). The genotypes of cluster IV had lowest mean value for plant height $(28.531 \mathrm{~cm})$. The genotypes of cluster $\mathrm{V}$ had lowest value for days to 50 per cent flowering (62.250 days) as well as for days to maturity (114.531 days). The genotypes of cluster VI had highest mean value for harvest index (55.971) followed by biological yield per plant (37.407) and seed yield per plant (20.819), the genotypes of this cluster also had maximum mean values for all the desirable characters and minimum values for $50 \%$ flowering and maturity. The genotypes of cluster VII had highest mean value for pods per plant (19.485). The genotypes of cluster VIII had average mean values for all the characters.

The genotypes of cluster IX had highest mean value for days to 50 per cent flowering (74.964) and had lowest mean value for 100 seed weight (14.752). The genotypes of Cluster X had average mean values for all the characters. The genotypes of cluster XI had lowest value for biological yield per plant (20.693). The genotypes of cluster XII had highest mean value for plant height (103.127) as well as for branches per plant (2.135). This analysis suggested that the genotypes of clusters I, VI and VII are the best genotypes for grain yield.

The analysis of character contributions towards genetic divergence among one hundred twenty genotypes and four check varieties of fieldpea are given in Table 4. The maximum contributions in manifestation of total genetic divergence were made by plant height $(77.52 \%)$, harvest index (14.56), days to 50 per cent flowering (2.50), days to maturity (2.16), biological yield per plant (2.05), 100 seed weight $(0.80)$ and pods per plant $(0.41)$. The minimum contributions in manifestation of total genetic divergence were made by branches per plant, seeds per pod, pod length and seed yield per plant (0.01). Similar results were reported by Shrivastava $e t$ al., (2012). 
Int.J.Curr.Microbiol.App.Sci (2018) 7(6): 1821-1826

Table.1 Clustering pattern of 120 fieldpea genotypes and four check varieties on the basis of non-hierarchical Euclidean cluster analysis

\begin{tabular}{|c|c|c|}
\hline $\begin{array}{l}\text { Cluster } \\
\text { No. }\end{array}$ & $\begin{array}{c}\text { Number of } \\
\text { genotypes }\end{array}$ & Genotypes \\
\hline II & 15 & $\begin{array}{l}\text { FP 14-22, FP 14-21, FP 14-67, FP 10-122, FP 11-51, KPMR-602, FP 2009-4, P-489, HFP-8909, HUDP-15, FP-14-79, } \\
\text { FP 10-131, FP 13-81, Pant P-137, FP 14-83. }\end{array}$ \\
\hline III & 9 & D-22, FP 11-108, FP 10-135, FP-572, FP 11-63, JPB-3,FP 13-6, FP 11-112, FP 11-93, \\
\hline IV & 4 & Pant-31, FP 14-15, FP 14-75, EC- 209288. \\
\hline $\mathbf{V}$ & 8 & FP 14-34, FP 14-89, FP-34, FP 14-88, FP 14-33, FP14-24, FP 13-33, FP 14-30. \\
\hline VI & 3 & FP 14-81, FP 11-72, EC-507770. \\
\hline $\mathbf{I X}$ & 12 & $\begin{array}{l}\text { FP 13-40, FP 11-105, FP 13-25, FP 11-113, KPMR-4, HUDP-15, FP 14-76, FP 13-97, HUDP-2, FP 13-14, P-1089, } \\
\text { DMR-63 }\end{array}$ \\
\hline$\overline{\mathbf{X}}$ & 15 & $\begin{array}{l}\text { FP 14-93, IPLK-85, HUP-16, IMD-83, FP 14-6, FP 14-31, FP 14-17, FP 14-12, FP 11-68, FP 14-25, IPLK-112, EC- } \\
\text { 392177, FP 14-28, EC-5459, P-1042. }\end{array}$ \\
\hline $\mathbf{X I}$ & 20 & $\begin{array}{l}\text { HFP-529, FP 13-39, HUP-2, EC-386742, KPMR-528, EC-538, TP-868, FP 13-90, FP 13-84, FP 13-31, FP 13-62, } \\
\text { HFP-4, FP 11-129, FP 13-59, FP 13-37, FP 10-32, DMR-48, FP 14-21, FP13-43, IPLK-117. }\end{array}$ \\
\hline
\end{tabular}

Table.2 Estimates of average intra and inter-cluster distance for 12 clusters in fieldpea genotypes

\begin{tabular}{|c|c|c|c|c|c|c|c|c|c|c|c|c|}
\hline & $\begin{array}{c}\text { Cluster } \\
\text { I }\end{array}$ & $\begin{array}{c}\text { Cluster } \\
\text { II }\end{array}$ & $\begin{array}{c}\text { Cluster } \\
\text { III }\end{array}$ & $\begin{array}{c}\text { Cluster } \\
\text { IV }\end{array}$ & $\begin{array}{c}\text { Cluster } \\
\text { V }\end{array}$ & $\begin{array}{c}\text { Cluster } \\
\text { VI }\end{array}$ & $\begin{array}{c}\text { Cluster } \\
\text { VII }\end{array}$ & $\begin{array}{l}\text { Cluster } \\
\text { VIII }\end{array}$ & $\begin{array}{c}\text { Cluster } \\
\text { IX }\end{array}$ & $\begin{array}{c}\text { Cluster } \\
\text { X }\end{array}$ & $\begin{array}{c}\text { Cluster } \\
\text { XI }\end{array}$ & $\begin{array}{c}\text { Cluster } \\
\text { XII }\end{array}$ \\
\hline Cluster I & 9.911 & 13.146 & 24.114 & 17.452 & 19.321 & 37.426 & 26.507 & 14.450 & 21.163 & 21.801 & 16.841 & 33.116 \\
\hline Cluster II & & 6.616 & 13.157 & 15.818 & 23.254 & 27.073 & 27.777 & 11.633 & 19.114 & 32.746 & 22.730 & 38.330 \\
\hline Cluster III & & & 7.707 & 17.880 & 23.773 & 24.968 & 37.441 & 19.068 & 23.356 & 39.206 & 37.186 & 50.247 \\
\hline Cluster IV & & & & 7.866 & 15.637 & 23.224 & 33.538 & 26.646 & 31.565 & 38.611 & 40.239 & 58.308 \\
\hline Cluster V & & & & & 6.617 & 19.262 & 23.378 & 20.308 & 29.548 & 23.290 & 33.534 & 40.500 \\
\hline Cluster VI & & & & & & 8.616 & 25.304 & 27.565 & 36.621 & 48.749 & 54.180 & 52.017 \\
\hline Cluster VII & & & & & & & 16.392 & 18.055 & 22.893 & 26.105 & 26.258 & 21.450 \\
\hline Cluster VIII & & & & & & & & 5.336 & 12.794 & 19.902 & 12.955 & 17.698 \\
\hline Cluster IX & & & & & & & & & 10.544 & 21.605 & 16.126 & 18.621 \\
\hline Cluster X & & & & & & & & & & 9.977 & 15.875 & 20.460 \\
\hline Cluster XI & & & & & & & & & & & 7.362 & 15.141 \\
\hline Cluster XII & & & & & & & & & & & & 6.801 \\
\hline
\end{tabular}

Bold figures indicate the intra-cluster distance

Table.3 Cluster mean for different characters in fieldpea genotypes

\begin{tabular}{|c|c|c|c|c|c|c|c|c|c|c|c|}
\hline Characters & $\begin{array}{c}\text { Days to } \\
50 \text { per } \\
\text { cent } \\
\text { flowering }\end{array}$ & $\begin{array}{c}\text { Days to } \\
\text { maturity }\end{array}$ & $\begin{array}{c}\text { Plant } \\
\text { height } \\
(\mathrm{cm})\end{array}$ & $\begin{array}{c}\text { Number } \\
\text { of Primary } \\
\text { branches/ } \\
\text { plant }\end{array}$ & $\begin{array}{c}\text { Number } \\
\text { of Pods/ } \\
\text { plant }\end{array}$ & $\begin{array}{c}\text { Number } \\
\text { of } \\
\text { Seeds/ } \\
\text { Pod }\end{array}$ & $\begin{array}{l}\text { Pod } \\
\text { length } \\
\text { (cm) }\end{array}$ & $\begin{array}{c}\text { 100-Seed } \\
\text { weight }\end{array}$ & $\begin{array}{l}\text { Biological } \\
\text { yield/ } \\
\text { plant }\end{array}$ & $\begin{array}{c}\text { Harvest } \\
\text { index } \\
\text { (per cent) }\end{array}$ & $\begin{array}{c}\text { Seed } \\
\text { yield/plan } \\
t(g)\end{array}$ \\
\hline Cluster I & 69.165 & 120.739 & 47.074 & $1.105^{*}$ & $12.813^{*}$ & 4.414 & 5.412 & $20.585^{* *}$ & 24.793 & 45.332 & 11.325 \\
\hline Cluster II & 74.708 & $125.706 * *$ & 51.540 & 1.199 & 13.603 & 5.350 & 6.141 & 20.470 & 28.425 & 51.593 & 14.794 \\
\hline Cluster III & 74.104 & 124.542 & 82.695 & 1.309 & 13.605 & $7.074 * *$ & $7.984 * *$ & 16.691 & 31.099 & 50.795 & 15.765 \\
\hline Cluster IV & 66.250 & 116.500 & $28.531 *$ & 1.339 & 13.229 & 6.438 & 6.999 & 19.652 & 30.724 & 53.390 & 16.571 \\
\hline Cluster V & $62.250^{*}$ & $114.531^{*}$ & 99.505 & 1.443 & 15.223 & 5.138 & 5.832 & 19.062 & 29.359 & 50.534 & 14.856 \\
\hline Cluster VI & 68.271 & 119.292 & 91.942 & 2.085 & 18.635 & 5.542 & 6.260 & 20.346 & $37.407 * *$ & $55.971 * *$ & $20.819 * *$ \\
\hline Cluster VII & 69.243 & 120.403 & 75.954 & 2.027 & $19.485^{* * *}$ & 3.303 & 4.479 & 20.346 & 29.137 & 43.459 & 12.422 \\
\hline Cluster VIII & 74.139 & 125.683 & 96.189 & 1.506 & 15.325 & 4.004 & 5.207 & 19.683 & 25.992 & 46.251 & 11.995 \\
\hline Cluster IX & $74.964 * *$ & 125.441 & 64.299 & 1.820 & 16.077 & 4.438 & 5.492 & $14.752 *$ & 25.450 & 40.502 & 10.308 \\
\hline Cluster X & 67.304 & 117.542 & 95.543 & 1.147 & 16.305 & 3.230 & 4.449 & 15.263 & 23.896 & 33.149 & 7.908 \\
\hline Cluster XI & 74.050 & 124.550 & 69.107 & 1.257 & 14.610 & 2.911 & 4.017 & 18.278 & 20.693* & 36.544 & 7.599 \\
\hline Cluster XII & 73.488 & 125.575 & $103.127 * *$ & $2.135^{* *}$ & 18.520 & $2.146^{*}$ & $3.695^{*}$ & 17.757 & 21.943 & $32.059 *$ & $6.936^{*}$ \\
\hline
\end{tabular}


Table.4 Contribution of characters towards genetic divergence

\begin{tabular}{|l|c|c|}
\hline \multicolumn{1}{|c|}{ Source } & \multicolumn{1}{|c|}{ Times ranked I } & Contribution per cent \\
\hline 1. Days to 50 per cent flowering & 191.000 & 2.50 \\
\hline 2. Days to maturity & 165.000 & 2.16 \\
\hline 3. Plant height (cm) & 5912.000 & 77.52 \\
\hline 4. Number of primary branches/plant & 0.000 & 0.01 \\
\hline 5. Number of pods/ plant & 31.000 & 0.41 \\
\hline 6. Number of seeds/ pod & 0.000 & 0.01 \\
\hline 7. Pod length (cm) & 0.000 \\
\hline 8. 100-Seed weight (gm) & 61.000 \\
\hline 9. Biological yield/ plant (g) & 156.000 \\
\hline 10. Harvest index (per cent) & 1110.000 \\
\hline 11. Seed yield/ plant (gm) & 0.000 \\
\hline
\end{tabular}

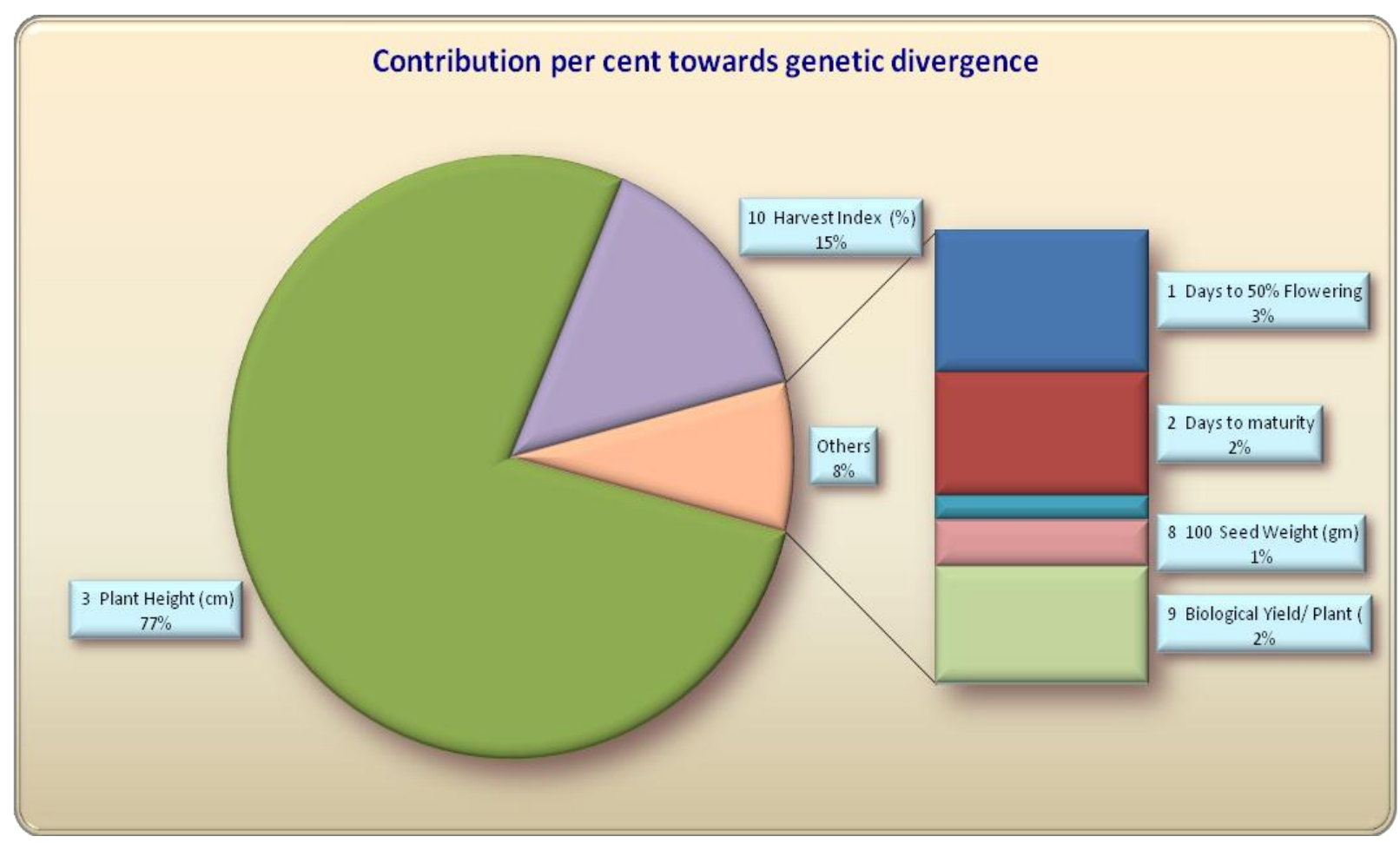

The overall review of the results obtained by genetic diversity analysis in the present investigation revealed that the crosses between the entries separated by the large inter-cluster distance and having high cluster mean values for one or other character to be improved is likely to be more useful. The results of Non-hierarchical Euclidian cluster analysis obtained under present study are also in agreement with the results of Khan et al., (2016), Quafi et al., (2016), Parihar et al., (2014), Shrivastava et al., (2012), Singh and Singh (2006).
From all over the analysis, it can be concluded that high amount of variability was present in the genotypes under study which provided a better opportunity to select desirable genotypes for further utilization in breeding programme. All the genotypes were grouped into twelve different non-overlapping clusters based on $\mathrm{D}^{2}$ values. The genotypes of Cluster VI namely, FP 14-81, FP 11-72 and EC-507770, are the best genotypes on the basis of their mean performance for seed yield and its contributing traits and these genotypes also showed a wide range of diversity with 
the genotypes of cluster XI. Therefore, the present study suggests that the genotypes for hybridization programme may be selected from cluster IV, XII, VI and cluster XI to generate the spectrum of variability for selection of transgressive segregants for high grain yield in field pea.

\section{References}

Beale, E. M. L. (1969). Euclidean cluster analysis. A paper contributed to 37th session of the International Statistical Institute.

Khan, M. R. A.; Mahbub, M. M.; Reza, M. A.; Shirazy, B. J. and Mahmud, F. (2016) Selection of Field Pea (Pisum sativum L.) Genotypes through multivariate analysis. Scientia Agriculturae, 16(3): 98-103.

Ouafi, L.; Alane, F.; Bouziane, H. R. and Abdelguerfi, A. (2016). Agro- morphological diversity within field pea (Pisum sativum L.) genotypes. African Journal of Agricultural Research, 11(40): 4039-4047.

Parihar, A. K.; Dixit, G. P.; Pathak, V. and Singh, D. (2014). Genetic diversity and trait inter-relationship studies in a diverse set of fieldpea (Pisum sativum L.) genotypes. Journal of Food Legumes, 27(4):297-301.

Shrivastava, V.; Lal, G. M.; Kunj, C. and Singh, C. M. (2012). Estimation of genetic divergence in field pea (Pisum sativum L.). Enviro. and Eco., 30(1): 136-138.

Singh, J.D. and Singh, J.P. (2006). Genetic divergence in advanced genotypes for grain yield in field pea (pisum sativum L.). Legume res., 29(4): 301 - 303.

Spark, D.N. (1973). Euclidean cluster analysis: Algorithm As.-58 Applied Statistics, 22: 126-136.

\section{How to cite this article:}

Kanhaiya Lal, Rajesh Kumar, Vishal Singh, Amit Kumar Chaudhary, Harikant Yadav and Ashvani Kumar. 2018. Evaluation of Genetic Divergence for Grain Yield and Its Contributing Traits in Field pea (Pisum sativum L. var. arvense). Int.J.Curr.Microbiol.App.Sci. 7(06): 18211826. doi: https://doi.org/10.20546/ijcmas.2018.706.217 